\title{
Consommation d'énergie par les ovins au pâturage, en montagne, pendant l'été
}

\author{
U Francia, G Catillo, S Dell'Aquila, AM Pilla \\ Istituto Sperimentale per la Zootecnia, via Salaria, \\ 31, 00016 Monterotondo Scalo, Rome, Italie
}

La connaissance de la quantité d'énergie consommée par les ovins au pâturage est très importante pour améliorer la production des animaux et l'exploitation de la prairie.

Au cours de 7 années, un troupeau de 250 brebis, de race "Gentile di Puglia" a pâturé une prairie naturelle d'altitude (1 600$1800 \mathrm{~m}$ ) de $36 \mathrm{ha}$, dans la région des Abruzzes. La prairie était divisée en 6 parcelles, et le temps de séjour des animaux était de $15 \mathrm{j}$ sur chacune d'elles. La consommation d'énergie a été estimée par différence entre la quantité d'énergie présente à l'entrée des animaux sur la parcelle, et à la sortie. Dans les échantillons séchés du fourrage récolté sous 8 cages de $1 \mathrm{~m}^{2}$ chacune par parcelle, on a déterminé la composition chimique ef la valeur nutritive (INRA, 1978). Les brebis ont été pesées avant et après la période de pâturage, et les poids ont été corrigés en fonction du stade de gestation. Les besoins théoriques ont été obtenus en calculant l'entretien, la production, la gestation, les variations de poids, et le besoin pour le déplacement (INRA, 1978).

Dans le tableau I, on a rapporté le poids moyen des brebis, les besoins estimés et la consommation moyenne d'énergie par les brebis au pâturage pendant les 7 années. L'accord entre les besoins estimés et la consommation calculée est très intéressant.

On peut donc utiliser ce résultat pour établir le chargement par ha dans les prairies de montagne de caractéristiques semblables.

INRA (1978) Alimentation des ruminants. INRA Publications, Versailles

Tableau l. Poids moyen des brebis $(\mathrm{kg})$, corrigé pour la gestation, et besoins et consommation d'énergie (UFL/brebis par $\mathrm{j}$ ).

\begin{tabular}{lcccccccc}
\hline Année & 1981 & 1982 & 1983 & 1984 & 1985 & 1986 & 1987 & Moyenne \\
\hline Poids moyen (kg) & 49,1 & 52,3 & 51,8 & 47,9 & 48,0 & 46,4 & 46,4 & 48,8 \\
Besoins énergétiques (UFL/j) & 1,07 & 1,58 & 1,42 & 1,04 & 0,97 & 1,06 & 0,98 & 1,16 \\
Consommation d'énergie (UFL/j) & 1,19 & 1,54 & 1,31 & 0,86 & 0,95 & 1,07 & 1,16 & 1,15 \\
\hline
\end{tabular}

